\title{
SURF1-related Charcot-Marie-Tooth disease type 4
}

INSERM

\section{Source}

INSERM. (1999). Orphanet: an online rare disease and orphan drug data base. SURF1related Charcot-Marie-Tooth disease type 4. ORPHA:391351

SURF1-related Charcot-Marie-T ooth disease type 4 is a subtype of Charcot-Marie-Tooth disease type 4 characterized by childhood onset of severe, progressive, demyelinating sensorimotor neuropathy manifesting with distal muscle weakness and atrophy of hands and feet, distal sensory impairment (vibration and pinprick) of lower limbs, lactic acidosis, areflexia and severely reduced motor nerve conduction velocities ( $25 \mathrm{~m} / \mathrm{s}$ or less). Patients may also present kyphoscoliosis, nystagmus, hearing loss, cerebellar ataxia and/or brain MRI abnormalities (putaminal and periaqueductal lesions). 